\title{
A polysaccharide from Lentinus edodes inhibits human colon cancer cell proliferation and suppresses tumor growth in athymic nude mice
}

\author{
Jinglin Wang ${ }^{1}$, Weiyong $\mathrm{Li}^{1}$, Xiao Huang ${ }^{1}$, Ying Liu ${ }^{3}$, Qiang $\mathrm{Li}^{1}$, Ziming Zheng ${ }^{1}$, \\ Kaiping Wang ${ }^{2}$ \\ ${ }^{1}$ Union Hospital of Huazhong University of Science and Technology, Department of Pharmacy, 430030, Wuhan, China \\ ${ }^{2}$ Hubei Key Laboratory of Nature Medicinal Chemistry and Resource Evaluation, Tongji Medical College of Pharmacy, Huazhong \\ University of Science and Technology, 430030, Wuhan, China \\ ${ }^{3}$ Renmin Hospital of Wuhan University, Department of Pharmacy, 430060, Wuhan, China
}

Correspondence to: Kaiping Wang, email: wkpzcq@126.com

Keywords: apoptosis, colon cancer, lentinan, nude mice, ROS

Received: July 25, $2016 \quad$ Accepted: November 14, 2016

Published: November 21, 2016

\section{ABSTRACT}

The antitumor effect of Lentinan is thought rely on the activation of immune responses; however, little is known about whether Lentinan also directly attacks cancer cells. We therefore investigated the direct antitumor activity of SLNT (a waterextracted polysaccharide from Lentinus edodes) and its probable mechanism. We showed that SLNT significantly inhibited proliferation of HT-29 colon cancer cells and suppressed tumor growth in nude mice. Annxein V-FITC/PI, DAPI, AO/EB and H\&E staining assays all showed that SLNT induced cell apoptosis both in vitro and in vivo. SLNT induced apoptosis by activating Caspase-3 via both intrinsic and extrinsic pathways, which presented as the activation of Caspases- 9 and -8 , upregulation of cytochrome $\mathrm{c}$ and the $\mathrm{Bax} / \mathrm{Bcl}-2$ ratio, downregulation of NF-KB, and overproduction of ROS and TNF-a in vitro and in vivo. Pretreatment with the caspase-3 inhibitor AC-DEVD-CHO or antioxidant NAC blocked SLNT-induced apoptosis. These findings suggest that SLNT exerts direct antitumor effects by inducing cell apoptosis via ROSmediated intrinsic and TNF-a-mediated extrinsic pathways. SLNT may thus represent a useful candidate for colon cancer prevention and treatment.

\section{INTRODUCTION}

Colon cancer is the second leading cause of cancerrelated deaths worldwide, accounting for over 1 million new cases and about half a million deaths per year $[1,2]$. Surgery is the primary treatment for colon cancer. For most patients with metastasis, however, systemic chemotherapy is needed to relieve symptoms and prolong life. Standard first-line chemotherapeutic regimens for colon cancer involved a combination of infusional 5-fluorouracil (5-FU), leucovorin and oxaliplatin or 5-FU, irinotecan and bevacizumab [3, 4]. However, theside effects associated with these chemotherapeutic strategies, which include diarrhea, nausea and vomiting, acute myocardial infarction and cerebrovascular accident, greatly decrease the patients' quality of life and can be fatal at times [5]. There is thus a great need to screen for natural products exhibiting antitumor activities with low toxicity and high efficacy.

Lentinus edodes (called Xianggu and Shiitake in China and Japan respectively) is a popular edible mushroom in East Asia and is frequently used in food and in folk medicine. As a foodstuff, it is appetizing and nourishing and has been cultivated for thousands of years. As a medicinal agent, L. edodes exhibits antifungal/ antibacterial, antiviral, antioxidant, immunomodulatory and antitumor activities [6]. Among the various bioactive molecules responsible for these activities, polysaccharides are the best known and most potent mushroom-derived substances. Lentinan, a $\beta-1,3$-glucan polysaccharide isolated from L. edodes, has been used clinically in Japan since the early 1980 s because of its immunomodulatory and antitumor effects [7-9]. Earlier findings suggest Lentinan exerts its antitumor effects by activating 
immune responses in the host rather than directly by attacking cancer cells. The antitumor activity of Lentinan was thought to require an intact T-cell component and was mediated through a thymus-dependent immune mechanism [10]. However, recent studies have shown that Lentinan directly inhibits proliferation of liver cancer cells (HepG2) [11], murine skin carcinoma cells (CH72) [12], and breast cancer cells (MCF-7) [13]. However, little is known about the mechanism underlying the direct antitumor activity of Lentinan.

In previous studies from our laboratory, waterextracted and alkali-extracted polysaccharides were isolated from the fruit bodies of L. edodes, and their chemical structures and conformations were determined $[11,14]$. Studies showed that the antitumor activity of Lentinan in H22- and S180-bearing Balb/c mice reflected immunomodulatory activity and induction of apoptosis $[11,15]$. Thus, in the current study, we explored the direct antitumor activity of SLNT (a water-extracted polysaccharide from L.edodes) on HT-29 human colon cancer cells and HT-29 tumor-bearing athymic nude mice to assess its direct antitumor effects in the absence of an intact T-cell component and shed new light on its mechanism of action.

\section{RESULTS}

\section{SLNT inhibited the proliferation of HT-29 cells and induced apoptosis}

To investigate the effects of water-extracted Lentinan (SLNT) on the proliferation of HT-29 cells, MTT assay was performed. A concentration dependent inhibitory effect was observed when HT-29 cells were exposed to SLNT $(0-1600 \mu \mathrm{g} / \mathrm{mL})$ for $48 \mathrm{~h}$ (Figure 1A). SLNT $(1600 \mu \mathrm{g} / \mathrm{mL})$ exhibited a strongest direct antitumor activity on HT-29 cells with $35.57 \%$ of cell viability.

Owing to apoptosis is considered as the main cell death mechanism, we next tested apoptosis by flow cytometry. In Figure 1B and 1C, SLNT significantly induced HT-29 cell apoptosis in a dose-dependent manner, with $20.26 \%, 31.80 \%$ and $48.50 \%$ of apoptotic rate, respectively, compared with the negative control (NC, 7.31\%). To further confirm it, $\mathrm{AO} / \mathrm{EB}$ and DAPI staining were performed. In $\mathrm{AO} / \mathrm{EB}$ staining, the images (Figure 1D) revealed that more apoptotic cells (condensed green or orange) and less normal cells (uniform green) existed in SLNT group than NC. In DAPI staining (a nuclear stain), NC cells displayed homogenous fluorescence with no evidence of fragmentation or chromatin condensation (Figure 1D) SLNT-treated cells had prominent DNA condensation. Altogether, these results showed that SLNT induced HT-29 cell apoptosis thereby exerting its direct antitumor effects.

\section{SLNT suppressed HT-29 tumor growth in nude mice and induced apoptosis}

We next investigated the effect of SLNT in vivo. Tumor volumes (Figure 2A) and the final tumor weights (Figure 2B) of mice were shown. Surprisedly, tumors in SLNT-receiving mice were smaller than that of NC mice. And the inhibition rates of SLNT $(0.2,1$ and $5 \mathrm{mg} / \mathrm{kg})$ were $17.88 \%, 48.87 \%$ and $57.90 \%$, respectively, while 5-FU was $67.23 \%$, compared with the NC (Table 1). These suggested that tumor growth was efficiently retarded in SLNT-receiving mice compared with unreceiving mice. Additionally, the photographs of mice and tumors took at the end of treatment also clearly showed the arrest of tumor growth (Figure 2C). Nevertheless, no changes were observed in spleen index (Table 1).

To further explore whether apoptosis was involved in prevention of tumor growth, we analyzed tumor tissues by H\&E staining. Marked apoptotic morphologic changes such as karyorrhexis and irregular arrangement of karyomorphism were observed in SLNT group. Conversely, NC group kept good original grown status with completed, well-regulated and clearly visible karyomorphism (Figure 2D). This suggested that SLNT also induced apoptosis in HT-29 tumor xenografts.

\section{SLNT activated Caspase-3 in HT-29 cells and in tumor xenografts}

To explore how SLNT induced HT-29 cell apoptosis, we examined the effect of SLNT on caspase-3, the key effector caspase which could induce apoptosis through cleavage of its substrates. Stimulation of HT-29 cells with SLNT caused a pronounced activation of caspase-3 (Figure 3A) while NC cells showed nearly no activation. Similar results were observed in tumor tissues measured by western blotting (Figure 3B) and immunohistochemistry (Figure 3C). These suggested that SLNT activated caspase-3 both in vitro and in vivo.

To ascertain the role of caspase-3 in SLNT-induced apoptosis, a caspase- 3 inhibitor (Ac-DEVD-CHO) was used. HT-29 cells were pre-incubated with Ac-DEVDCHO $(25 \mu \mathrm{M})$ for $1 \mathrm{~h}$ before the addition of SLNT $(800 \mu \mathrm{g} / \mathrm{mL})$. In Figure 3D and 3E, the addition of AcDEVD-CHO significantly prevented SLNT-induced apoptosis (from $32.91 \pm 1.21 \%$ decreased to $15.88 \pm$ $1.58 \%$ while $\mathrm{NC}$ and Ac-DEVD-CHO group were $6.45 \pm$ $0.96 \%, 7.77 \pm 0.79 \%$, respectively). However, SLNT+AcDEVD-CHO group $(15.88 \pm 1.58 \%)$ was still higher than Ac-DEVD-CHO group $(7.77 \pm 0.79 \%)$. These suggested that SLNT-induced apoptosis depended to a large degree on the activation of caspase-3. 
Table 1: The final tumor weight, inhibition rate and spleen index of nude mice

\begin{tabular}{lccc}
\hline & Final tumor weight $(\mathbf{g})$ & Inhibition rate $\mathbf{( \% )}$ & Spleen index $(\mathbf{m g} / \mathbf{g})$ \\
\hline Negative control & $1.01 \pm 0.27$ & - & $1.13 \pm 0.09$ \\
SLNT $(0.2 \mathrm{mg} / \mathrm{kg})$ & $0.83 \pm 0.17$ & 17.88 & $1.32 \pm 0.28$ \\
SLNT $(1.0 \mathrm{mg} / \mathrm{kg})$ & $0.60 \pm 0.13^{*}$ & 48.87 & $1.19 \pm 0.15$ \\
SLNT $(5.0 \mathrm{mg} / \mathrm{kg})$ & $0.42 \pm 0.15^{* *}$ & 57.90 & $1.16 \pm 0.12$ \\
5 -FU $(20 \mathrm{mg} / \mathrm{kg})$ & $0.33 \pm 0.10^{* *}$ & 67.23 & $1.22 \pm 0.40$ \\
\hline
\end{tabular}

SLNT and 5-FU were administered intravenously every other day for 21 days, $24 \mathrm{~h}$ after subcutaneously injection of HT-29 cells. Mice were sacrificed 3 weeks after treatments. Inhibition rate was measured as described in Materials and methods. Spleen index was expressed as: spleen weight/body weight. All data are presented as means $\pm \operatorname{SD}(n=6) .{ }^{*} p<0.05$, $* * p<0.01$ versus NC.

\section{SLNT activated caspasese-9 and upregulated cytosolic Cytochrome $\mathrm{c}$ and the ratio of $\mathrm{Bax} / \mathrm{Bcl}-2$}

We next examined the effect of SLNT on the intrinsic mitochondrial apoptosis-related proteins, cleaved caspase-9, cytochrome c, Bax and Bcl-2. As shown in Figure 4A and 4B, caspase-9 was activated, cytosolic cytochrome $\mathrm{c}$ and Bax increased while Bcl-2 decreased in SLNT-treated cells compared to NC. The ratio of Bax/ Bcl-2 of SLNT-treated cells was about 3 fold higher than untreated cells. Consistent results were also observed in SLNT-treated HT-29 tumor xenografts (Figure 4C and 4D). These suggested that SLNT might induce HT-29 cell apoptosis via mitochondrial apoptotic pathway.

\section{SLNT induced the loss of mitochondrial membrane potential (MMP)}

Owing to the loss of MMP was a key event in the early apoptosis through mitochondrial apoptotic pathway, we detected the changes of MMP by JC-1 staining. Obviously, after incubated with SLNT, cells with green fluorescence

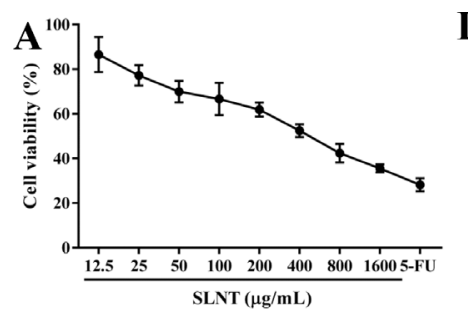

B
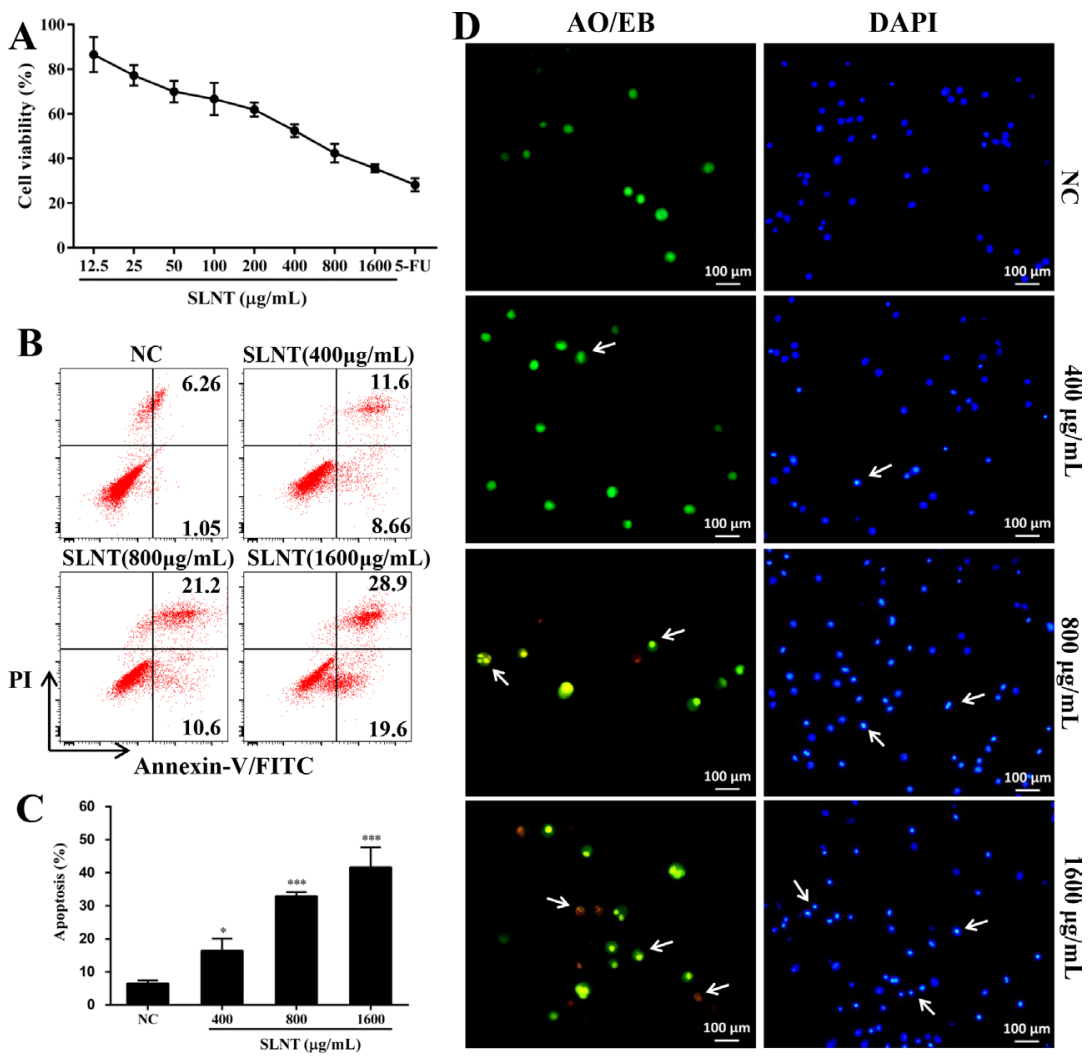

Figure 1: SLNT inhibited HT-29 cell proliferation and induced apoptosis. The cell viability was evaluated by MTT assay (A). Annexin V-FITC/PI staining was used to analyze apoptosis; representative results (B) and summative data $(\mathbf{C})$ from three independent experiments were shown. Cells treated with 400,800 and $1600 \mu \mathrm{g} / \mathrm{mL}$ of SLNT or without for $48 \mathrm{~h}$ were stained with AO/EB (green/ orange) or DAPI (blue) (D). Each bar represents means $\pm \mathrm{SD}(n=3) .{ }^{*} p<0.05,{ }^{* * *} p<0.001$ versus negative control (NC) group. 


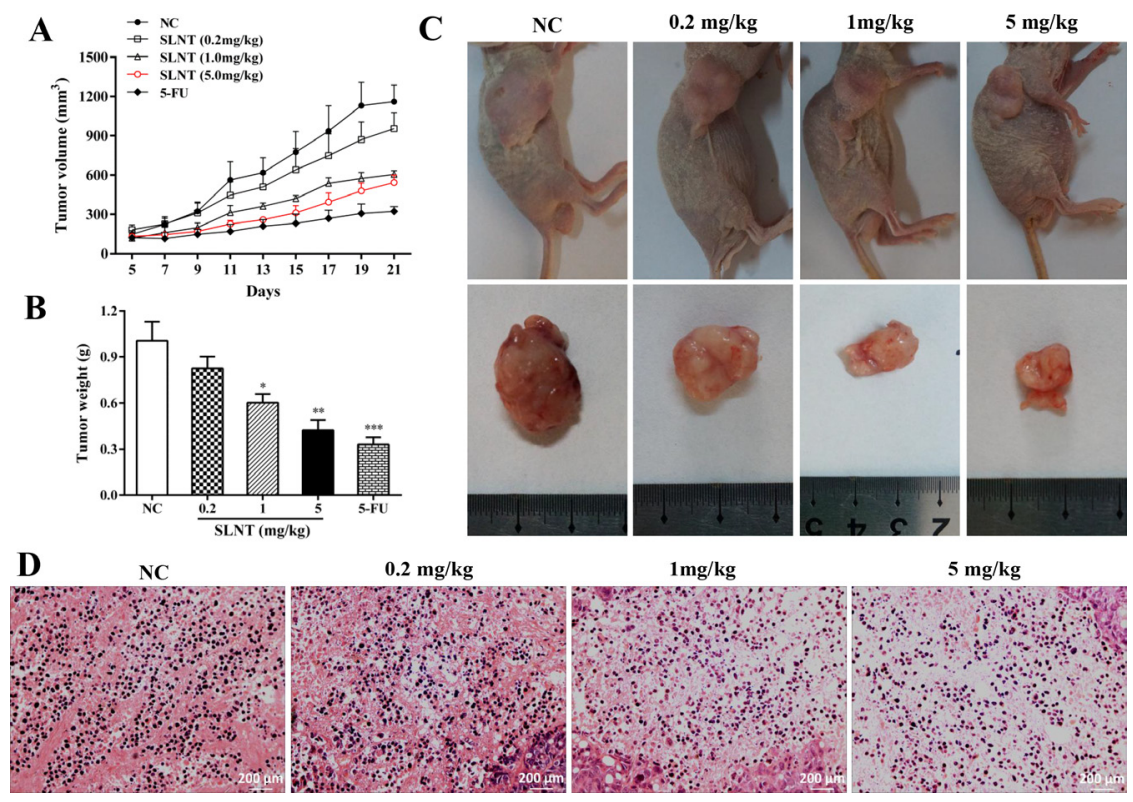

Figure 2: Inhibition and apoptotic induction effect of SLNT on HT-29 xenografts. Tumor volume from day 5 to day 21 (A) and tumor weights at the end of treatments were measured (B) Columns, mean $\pm \operatorname{SD}(n=6) ;{ }^{*} p<0.05,{ }^{* *} p<0.01,{ }^{* * *} p<0.001$ versus NC group. Photographs of nude mice and tumors of each group were taken at end of experiment $(\mathbf{C})$ Representative histopathological changes of apoptosis in tumors were analyzed by H\&E staining $(400 \times, \mathbf{D})$.
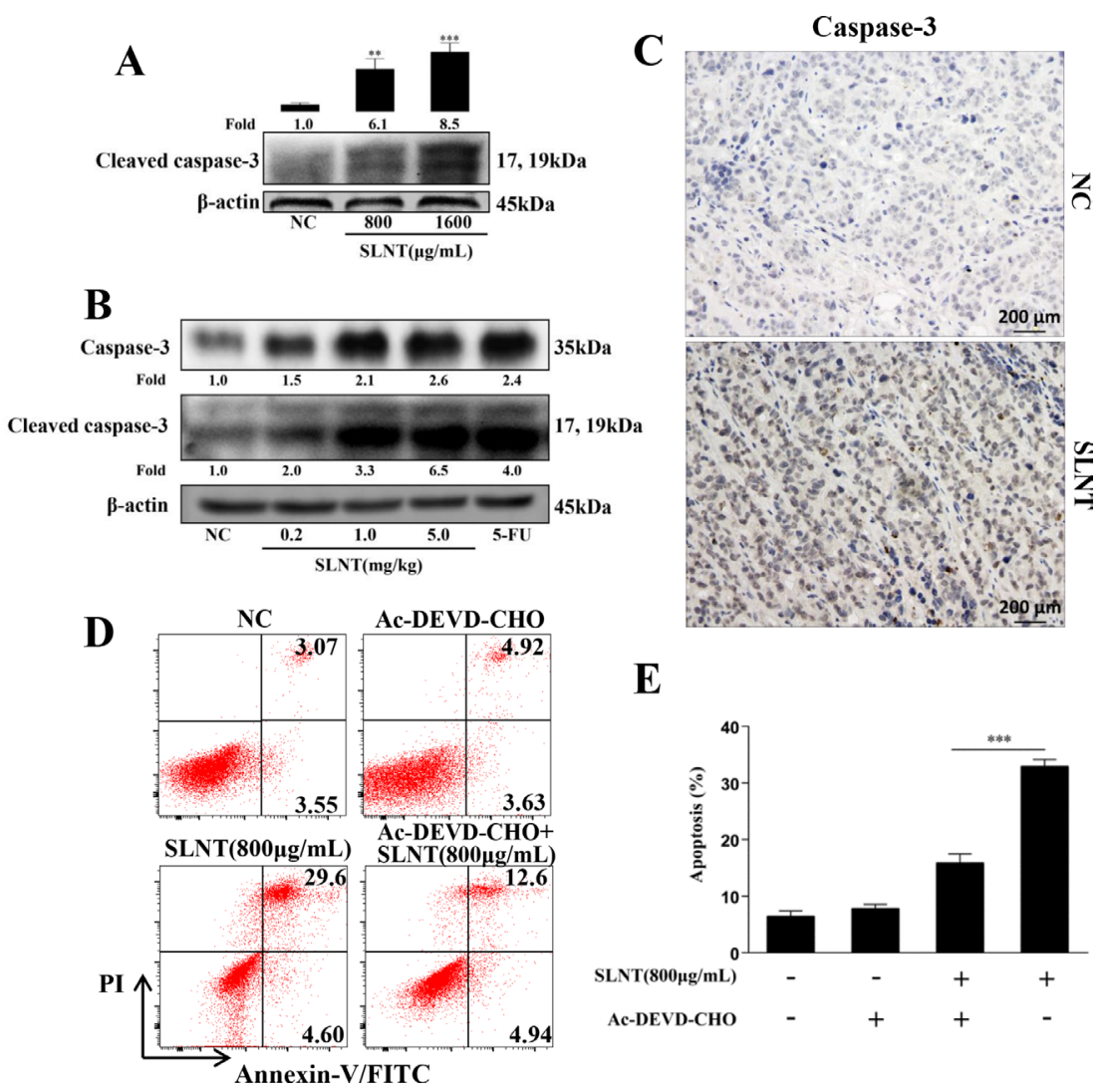

$\mathbf{E}$

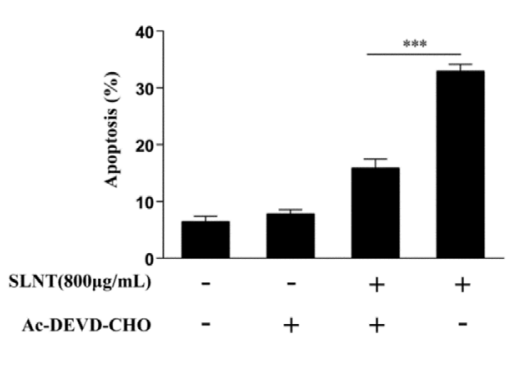

Figure 3: SLNT induced HT-29 cell apoptosis by activation of caspase-3 in cells and in tumors. Activity of caspase-3 in cells (A) and in tumor xenografts (B) was measured by western blot. Immunohistochemistry analysis of caspase-3 in tumors of SLNT $(5.0 \mathrm{mg} / \mathrm{kg})$ and $\mathrm{NC}$ were shown $(\mathbf{C}, 400 \times)$. HT-29 cells were incubated with SLNT $(800 \mu \mathrm{g} / \mathrm{mL})$, a caspase-3 inhibitor Ac-DEVD-CHO $(25 \mu \mathrm{M})$ or combination for $48 \mathrm{~h}$, representative results $(\mathbf{D})$ and summative data $(\mathbf{E})$ were shown. Each bar represents means $\pm \mathrm{SD}(n=3)$. ${ }^{* *} p<0.01,{ }^{* * *} p<0.001$ versus NC; ${ }^{\# \# \#} p<0.001$ versus combination group. 
significantly increased from $6.39 \%$ to $15.1 \%, 25.7 \%$ and $31.9 \%$ in order, and the ratio of green/red was remarkably higher than control (Figure 5A). The fluorescence pictures were shown (Figure 5B), which further confirmed the loss of $\Delta \Psi_{\mathrm{m}}$. These results suggested that SLNT indeed activated mitochondrial apoptotic pathway.

\section{SLNT increased the generation of ROS in HT-29 cells and in nude mice}

As ROS generated during oxidative stress is known to activate the intrinsic apoptosis, we next determined the effect of SLNT on generation of ROS. Compared to NC cells, SLNT significantly enhanced cellular ROS, particularly in a dose of $1600 \mu \mathrm{g} / \mathrm{mL}$ (Figure 6A and 6B). The photographs taken by fluorescence microscope also clearly showed increased ROS after stimulating with SLNT (Figure 6C). Additionally, significantly enhancement of ROS in serum of SLNT (1.0 and $5.0 \mathrm{mg} / \mathrm{kg}$ )-receiving mice were observed (Figure 6D).

To evaluate whether the upregulation of ROS activated intrinsic apoptosis, an antioxidant NAC was used. HT-29 cells were pre-incubated with NAC $(5 \mu \mathrm{M})$ for $1 \mathrm{~h}$ before SLNT $(800 \mu \mathrm{g} / \mathrm{mL})$ was added. As shown in Figure $7 \mathrm{~A}$ and $7 \mathrm{~B}$, the apoptotic rate of cells treated with SLNT $(800 \mu \mathrm{g} / \mathrm{mL})$ significantly decreased from $32.91 \pm 1.21 \%$ to $21.49 \pm 1.62 \%$ after pre-incubation of NAC, compared with NAC group (6.94 $\pm 0.57 \%)$.
Meanwhile, SLNT-induced upregulation of cytosolic cytochrome $\mathrm{c}$ and $\mathrm{Bax} / \mathrm{Bcl}-2$ were blocked by NAC (Figure 7C and 7D). These results indicated that ROS might act as upstream for activating intrinsic pathway. However, interestingly, there were still about 20\% apoptotic cells existed when ROS was largely cleaned out. This suggested that SLNT induced apoptosis maybe not only through intrinsic pathway, but also extrinsic pathway.

\section{SLNT activated Caspase-8 and prevented NF- $\mathrm{NB}$ activation and increased TNF- $\alpha$ levels in vitro and in vivo}

To ascertain whether extrinsic pathway was involved in SLNT-induced apoptosis, we analyzed activation of the key initiator caspase-8. Western blot showed that Caspase- 8 was activated both in vitro (Figure 8A) and in vivo (Figure $8 \mathrm{~B}$ ). Additionally, Caspase- 8 activity in cells and in tumors were analyzed by Caspase- 8 colorimetric activity kit (Figure 8C) and immunohistochemistry (Figure 8D), respectively. The results showed that SLNT activated caspase- 8 both in vitro and in vivo, suggesting SLNT might also activate caspase-8-mediated extrinsic apoptotic pathway. At the same time, we evaluated the nuclear translocation of NF- $\kappa \mathrm{B}$ p65 using western blot and immunofluorescence. Western blot (Figure $8 \mathrm{~A}$ and $8 \mathrm{~B}$ ) and immunofluorescence (Figure 9) revealed that SLNT induced an obvious decrease of NF- $\mathrm{B}$ p 65 nuclear translocation
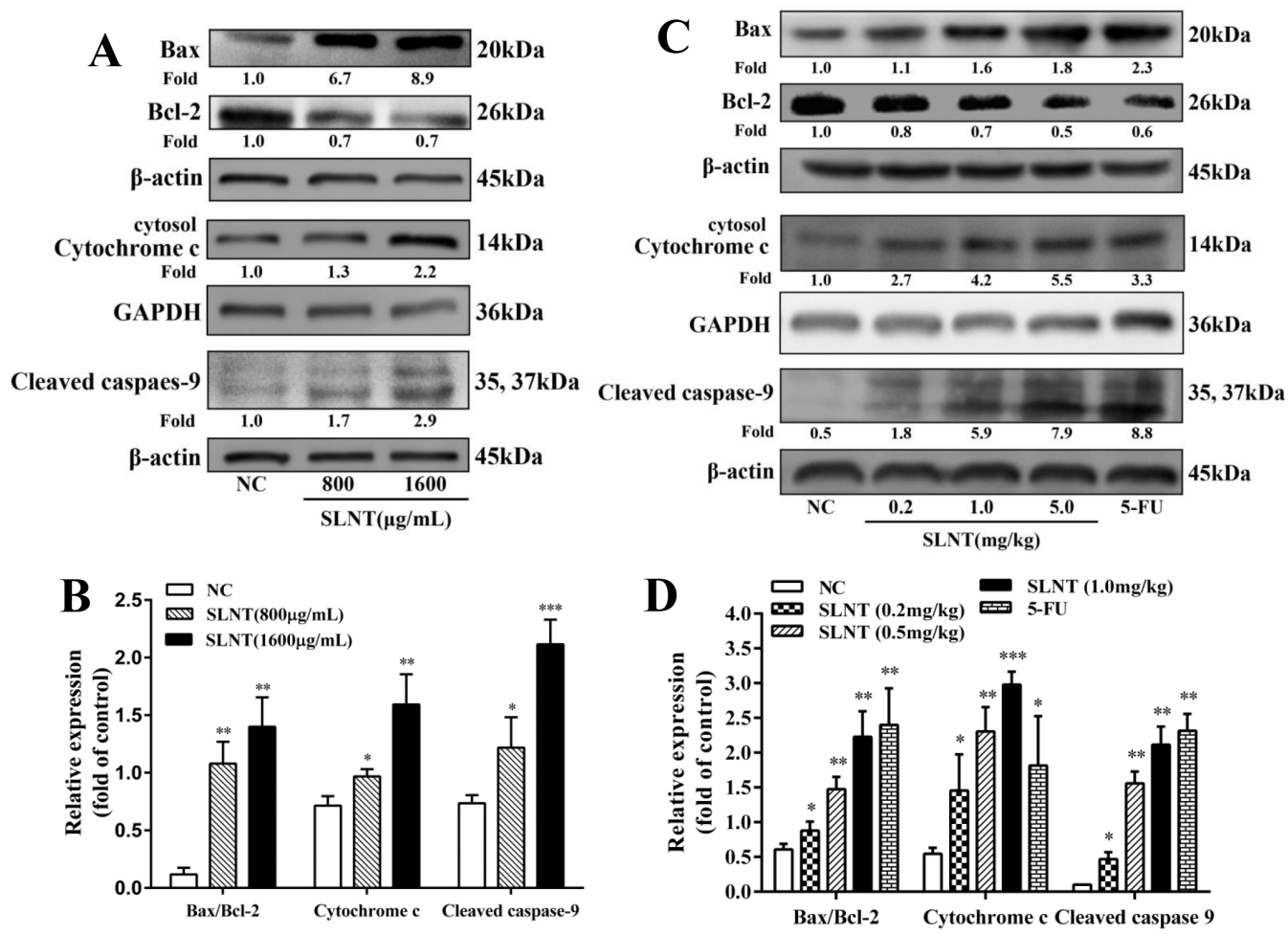

Figure 4: Effect of SLNT on intrinsic apoptotic-related proteins in cells and in tumors. Expression of Bax, Bcl-2, cytosolic Cytochrome c and Cleaved caspase-9 in cells (A, B) and in tumor xenografts (C, D) were analyzed by western blot in three independent experiments. Each bar represents means $\pm \mathrm{SD}(n=3),{ }^{*} p<0.05,{ }^{* *} p<0.01,{ }^{* * *} p<0.001$ versus NC group. 

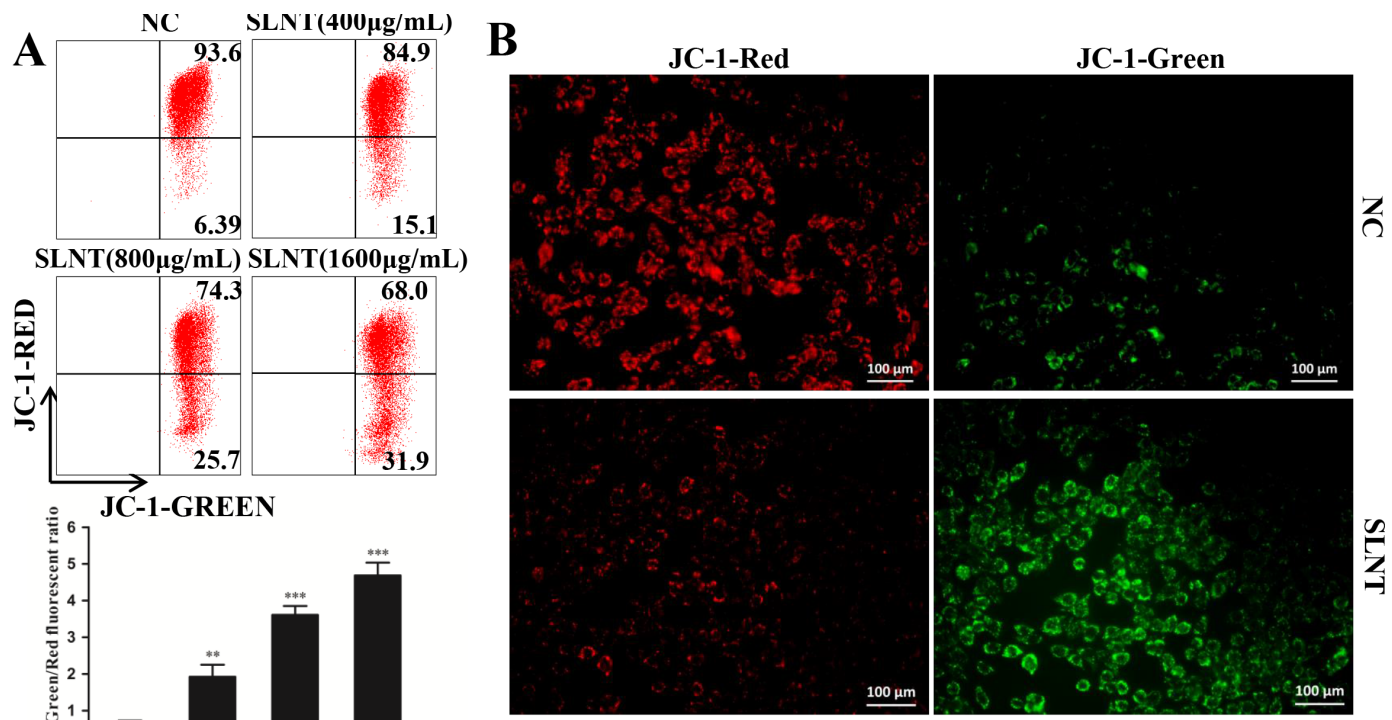

Figure 5: SLNT induced the loss of mitochondrial membrane potential (MMP) in cells. The change of MMP was analyzed by flow cytometry (A) and fluorescence microscope (B, 400×). Representative images of NC and SLNT ( $800 \mu \mathrm{g} / \mathrm{mL})$ taken by fluorescence microscope were shown.
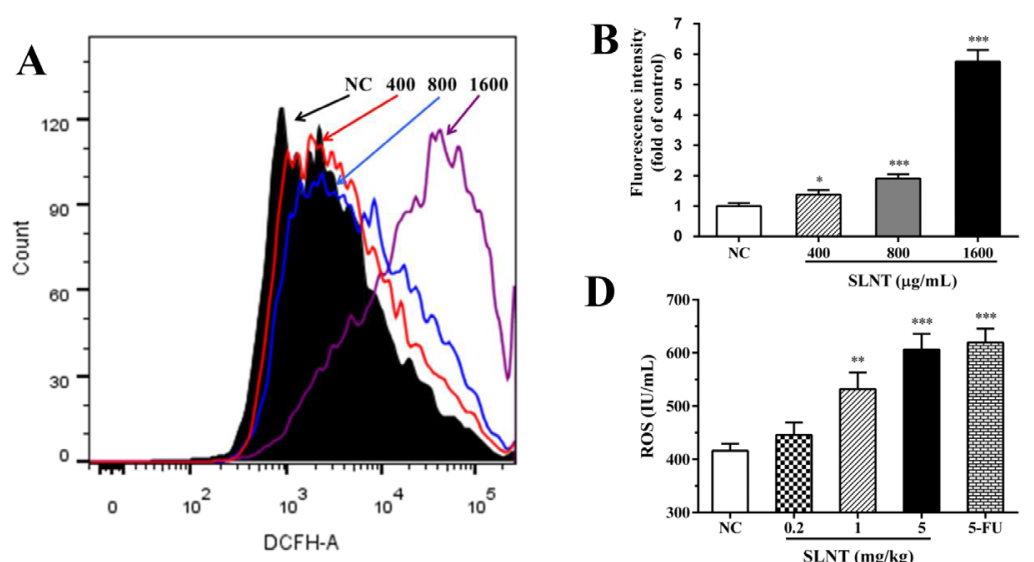

D
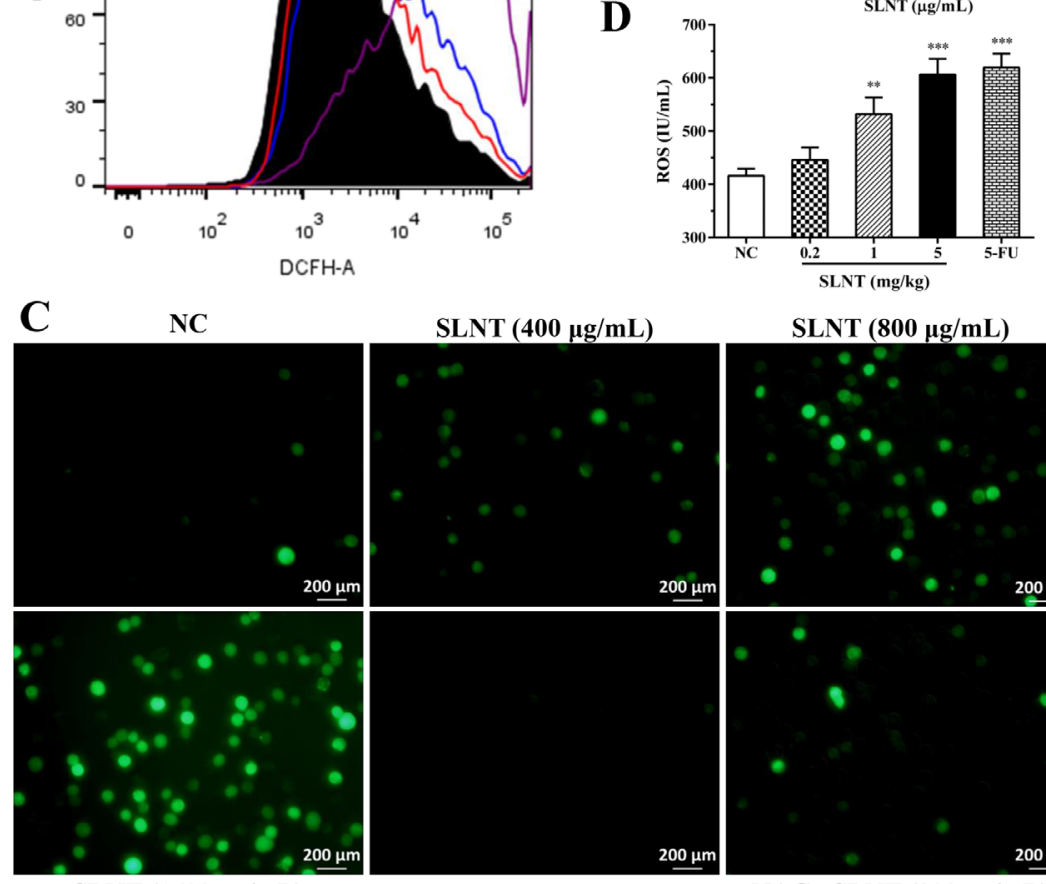

SLNT $(400 \mu \mathrm{g} / \mathrm{mL})$

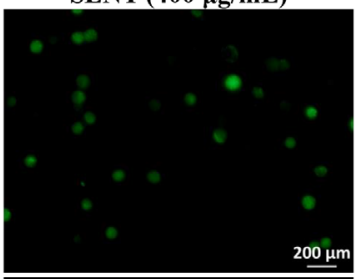

SLNT $(800 \mu \mathrm{g} / \mathrm{mL})$

SLNT $(1600 \mu \mathrm{g} / \mathrm{mL})$
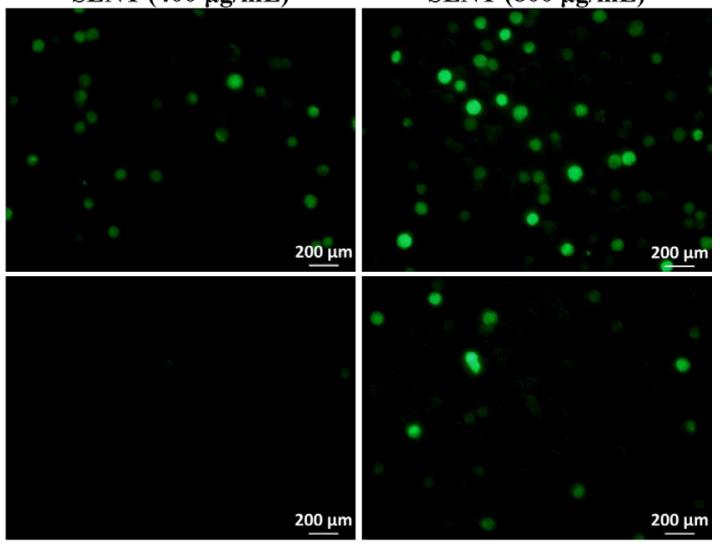

NAC+ SLNT $(800 \mu \mathrm{g} / \mathrm{mL})$

Figure 6: SLNT increased the generation of ROS in cells and in nude mice. Cellular ROS was measured by DCFH-DA using flow cytometry: a mixture image of NC (black), $400 \mu \mathrm{g} / \mathrm{mL}$ (red), $800 \mu \mathrm{g} / \mathrm{mL}$ (blue) and $1600 \mu \mathrm{g} / \mathrm{mL}$ (purple) of SLNT was shown (A), and fluorescence intensity were summarized (B); representative images $(\mathbf{C}, 400 \times)$ were taken by fluorescence microscope. The level of ROS in serum of nude mice was detected by ELISA assay (D). Each bar represents means $\pm \operatorname{SD}(n=3-6),{ }^{*} p<0.05,{ }^{* *} p<0.01,{ }^{* * *} p<0.001$ versus NC group. 
compared with NC both in cells and in tumors. Additionally, ELISA assay showed that TNF- $\alpha$ in serum (one of cytokines could activate extrinsic pathway) was enhanced after treated with SLNT ( Figure 8E). We next measured TNF- $\alpha$ levels in cell culture medium after SLNT treatment. Results indicated that TNF- $\alpha$ was significantly increased after stimulated by SLNT, which were consistent with the outcomes in vivo (Figure 8F).

\section{DISCUSSION}

Up to now, it was generally assumed that Lentinan mainly exerted its anti-tumor effects by enhancing immune responses, relying in particular on an intact T-cell component. In present study, however, SLNT exhibited direct anti-tumor effects against HT-29 cells by suppressing cell proliferation and inducing cell apoptosis through ROS-mediated intrinsic and TNF- $\alpha-$ mediated extrinsic apoptotic pathways.

Apoptosis plays a crucial role in controlling tumorigenesis, and the incidence of apoptosis reportedly as colonocytes progress from normal epithelium to carcinoma [16, 17]. Up-regulation of Bcl-2, downregulation of $\mathrm{Bax}$, and p53 mutations have been suggested as possible candidates responsible for the change [18]. Therefore, induction of apoptosis is a promising strategy for the prevention and treatment of colon cancer [19]. In present study, SLNT suppressed HT-29 cells proliferation (Figure 1A) and significantly induced its apoptosis (Figure 1B-1D), indicating that SLNT exerted direct antitumor effect in vitro. Previous works revealed that Lentinan inhibited tumor growth in H22- and S180-bearing Balb/c mice through immunostimulation (greatly enhanced thymus index and spleen index) and the induction of apoptosis. In current study, SLNT $(1.0$ and $5.0 \mathrm{mg} / \mathrm{kg}$ ) significantly suppressed tumor growth in athymic nude mice (Figure $2 \mathrm{~A}-2 \mathrm{C}$ ) with no changes in the spleen index (Table 1). This suggests the thymus may play key role in the immunoenhancement elicited by SLNT. At the same time, H\&E staining showed that SLNT induced apoptosis within tumor tissues (Figure 2D), indicating direct antitumor activity that may have played a crucial role in this case.

Caspases, the central mediators of the apoptotic pathway, act as initiators or effectors [20]. Once activated, initiator caspases (caspase-2, -8, -9 and -10) cleave and activate downstream effector caspases (caspase-3, -6 and -7), which then cleave multiple intracellular proteins to induce apoptosis [21]. Caspase-3 is an essential effector caspase acting in both the intrinsic and extrinsic apoptosis pathways [22]. In this study, we demonstrated that SLNT activated caspase-3 in HT-29 cells and within tumors (Figure 3A-3C). The caspase-3 inhibitor Ac-DEVD-CHO significantly inhibited SLNT-induced apoptosis, though the effect was not complete (Figure 3E). This suggests SLNT-induced apoptosis depends to a large degree on activation of caspase-3, but caspase-3-independent pathways may also exist and require further investigation.
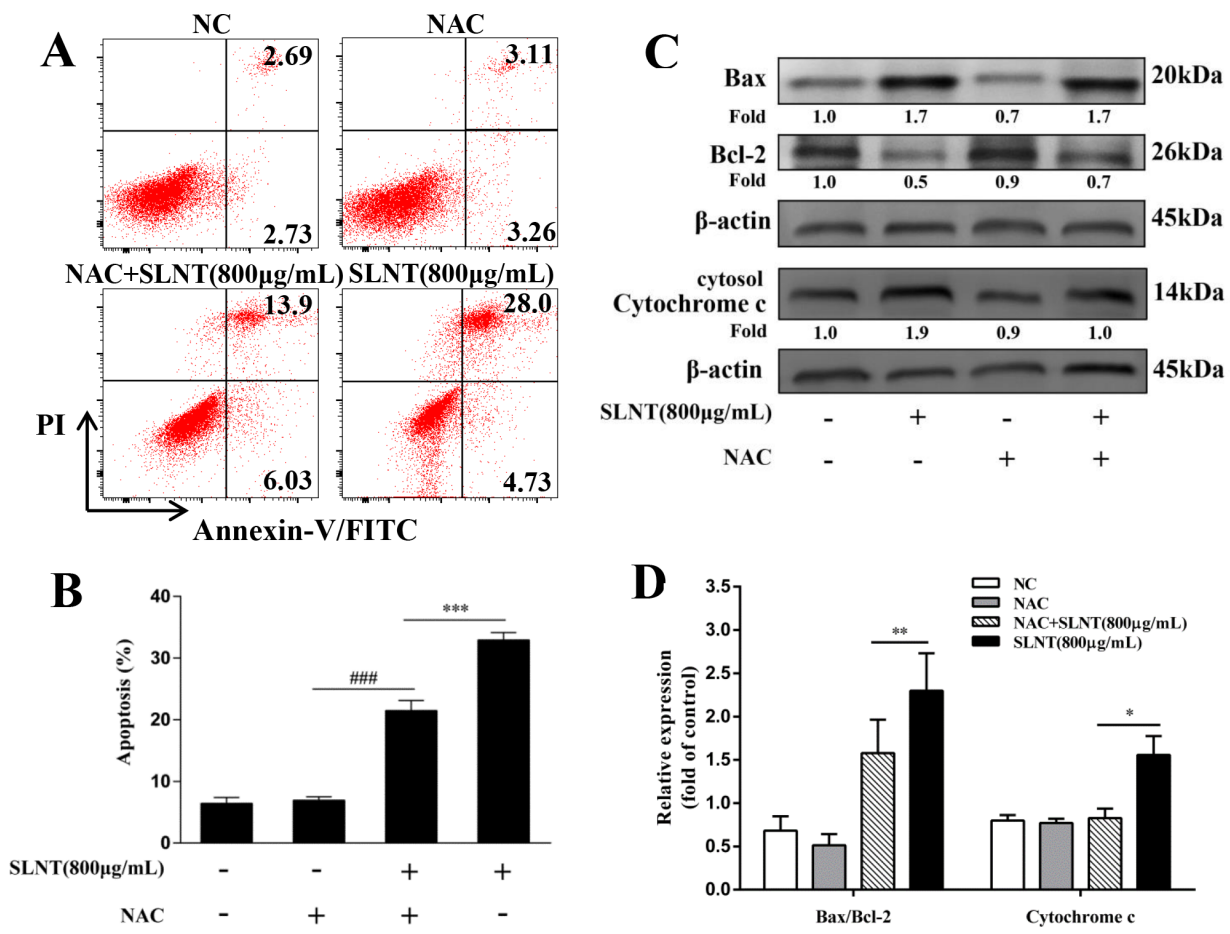

Figure 7: ROS was responsible for the SLNT-induced intrinsic apoptosis. HT-29 cells were incubated with SLNT $(800 \mu \mathrm{g} / \mathrm{mL})$, an antioxidant NAC $(5 \mu \mathrm{M})$, or combination for $48 \mathrm{~h}$. Annexin V-FITC/PI staining was used to analyze cell apoptosis $(\mathbf{A}, \mathbf{B})$, ${ }^{* * *} p<0.001$ versus combination group, ${ }^{\# \#} p<0.001$ versus NAC group. The expression of Bax, Bcl-2 and cytosol Cytochrome $\mathrm{c}$ were measured by western blot $(\mathbf{C})$ and summarized (D). Each bar represents means $\pm \operatorname{SD}(n=3),{ }^{*} p<0.05,{ }^{* *} p<0.01$ versus combination group. 
Apoptosis is triggered via intrinsic (mitochondrial) and extrinsic (death receptor) pathways [23]. The intrinsic pathway is activated by the loss of MMP and the release of cytochrome c from mitochondria into the cytosol. Once released, cytochrome c interacts with Apaf-1, ATP and procaspase- 9 to form the apoptosome, which cleaves and activates caspase- 9 and leads to activation of effector caspases [24-26]. Members of the anti-apoptotic $\left(\mathrm{Bcl}-2, \mathrm{Bcl}-\mathrm{X}_{\mathrm{L}}\right)$ and pro-apoptotic (Bax, Bad and Bid) Bcl-2 superfamily are intimately involved in the loss of MMP and release of cytochrome c [27], and the balance between these two groups is a critical regulator of this process $[28,29]$. We found that SLNT treatment resulted in the loss of MMP (Figure 5) with significantly increased Bax and decreased Bcl-2 in vitro and in vivo, which led to the release of cytochrome $\mathrm{c}$ and activation of caspase-9 (Figure 4A-4D). Thus SLNT activated the intrinsic mitochondrial apoptosis pathway.
ROS arising from normal metabolism and xenobiotic exposure can be beneficial or harmful, depending on their concentration [30]. Overproduction of ROS is an upstream factor contributing to the activation of the mitochondrial apoptotic pathway [31, 32]. Here, we demonstrated that SLNT significantly increased ROS in vitro and in vivo (Figure 6A-6D), and the antioxidant NAC greatly inhibited SLNT-induced apoptosis (Figure 7A and 7B) and blocked up-regulation of cytosolic cytochrome $\mathrm{c}$ and $\mathrm{Bax} / \mathrm{Bcl}-2$ in cells (Figure $7 \mathrm{C}$ and 7D). This suggests ROS act as upstream mediators of SLNT-induced intrinsic apoptosis. However, NAC did not completely protect HT-29 cells from SLNT-induced apoptosis, suggesting the involvement of both ROSdependent and -independent mechanisms. We therefore also considered the extrinsic apoptotic pathway.

The extrinsic apoptotic pathway is initiated by TNF- $\alpha$ binding to TNFR1 or FasL binding to Fas
A

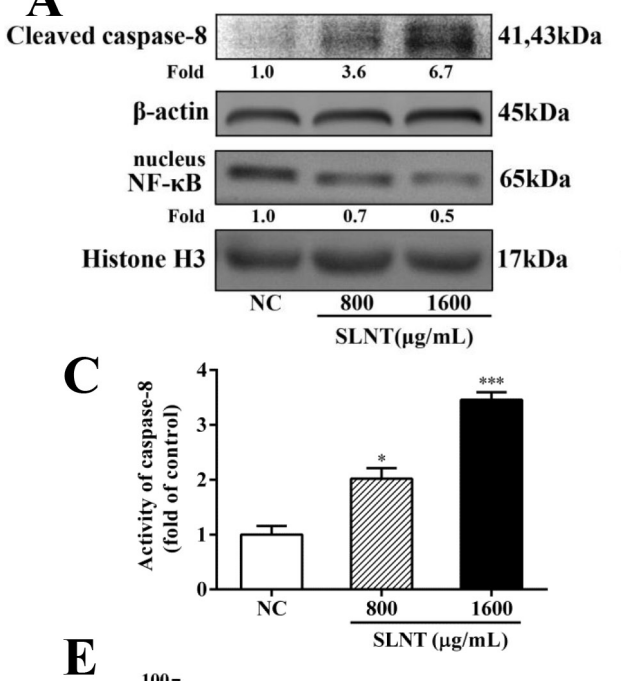

E

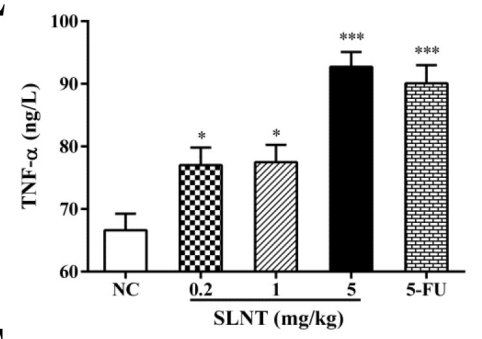

F

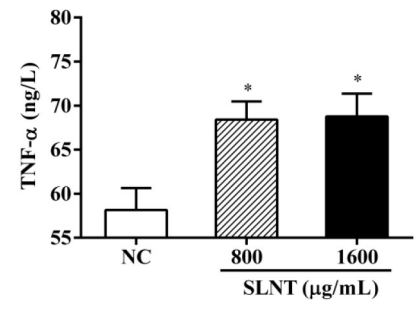

B

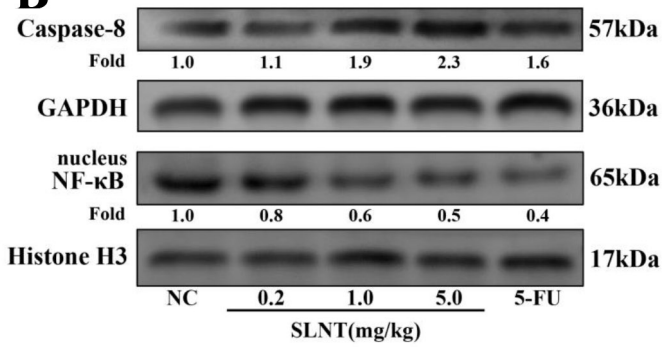

D

Cleaved caspase-8

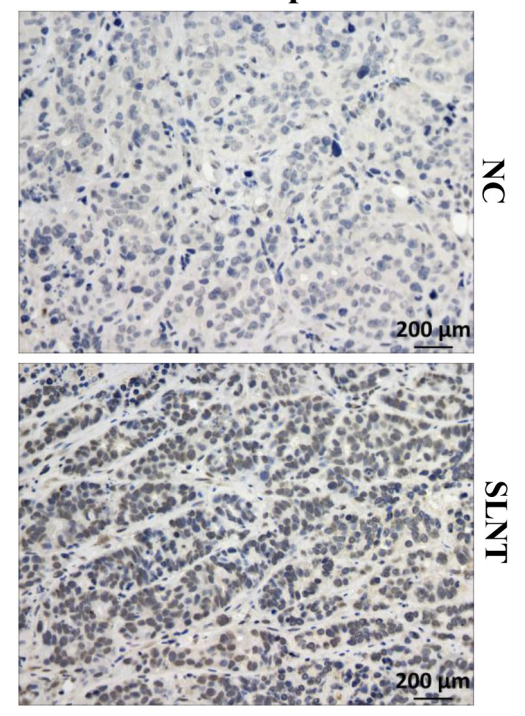

Figure 8: SLNT activated caspase-8, decreased nuclear NF-кB and increased TNF- $\alpha$ in vitro and in vivo. Expression of cleaved caspase-8 and nuclear NF- $\mathrm{kB}$ in cells (A) and in tumors (B) were analyzed by western blot. Activity of caspase-8 in cells was further measured by Caspase- 8 activity kit (C). Immunohistochemistry analysis of cleaved caspase-8 in NC and in SLNT (5.0 mg/kg) tumors was shown (D). The level of TNF- $\alpha$ in serum of nude mice $(\mathbf{E})$ and in cell culture medium (F) was measured by ELISA assay. Each bar represents means $\pm \mathrm{SD}, n=3-6,{ }^{*} p<0.05,{ }^{* * *} p<0.001$ versus NC group. 
receptors. These associations lead to recruitment of adaptor molecules such as FADD and, in turn, activation of initiator caspase-8, and the caspase cascade, culminating in apoptosis [24]. Caspase- 8 also can indirectly activate caspase- 3 through cleavage of Bid to its truncated form (t-Bid) [33]. In present study, SLNT treatment led to ncreases in TNF- $\alpha$ levels and the activation of caspase-8, and thus the extrinsic apoptoic pathway, in vitro and in vivo (Figure 8). Unlike the rapid apoptosis induced by FasL, however, apoptosis is a late response to TNF- $\alpha$ [34]. TNF- $\alpha$ binding to TNFR-1 can also activate NF$\kappa \mathrm{B}$, which inhibits of apoptosis through induction of anti-apoptotic factors [35]. Only when NF- $\kappa B$ activation is insufficient is apoptosis induced through caspase- 8 activation. We found that SLNT effectively inhibited nuclear translocation of NF- $\kappa \mathrm{B}$ in HT-29 cells and tumors (Figure 8A-8B and Figure 9).

In sum, our findings demonstrate that SLNT induces apoptosis through two pathways: (i) the intrinsic pathway mediated through overproduction of ROS, loss of MMP, increases in the Bax/Bcl-2 ratio and cytosolic cytochrome c, and activation caspase-9 and -3 ; (ii) the extrinsic pathway mediated through increases in TNF- $\alpha$, inhibition of NF- $\kappa \mathrm{B}$, and activation of caspase-8 and -3 (Figure 10). Altogether, SLNT exerts direct antitumor effects on colon cancer cells both in vitro and in vivo. This suggests SLNT may be an effective natural agent for use in therapy against colon cancer.

\section{MATERIALS AND METHODS}

\section{Reagents and antibodies}

McCoy's 5A medium, fetal bovine serum (FBS), penicillin-streptomycin and trypsin-EDTA were obtained from Gibco (Grand Island, NY, USA). NAC, Ac-DEVDCHO, DAPI and AO\&EB, DCFH-DA, JC-1 stain kit, Cell and Tissue mitochondria isolation kits, Caspase- 8 activity assay kit and BCA protein assay kit were obtained from Beyotime Biotech (Jiangsu, China). Nuclear-Cytosol kit was obtained from Applygen Technologies Inc (Beijing, China). Annexin V-FITC/PI assay kit, ROS and TNF- $\alpha$ ELISA kits were purchased from KeyGEN Biotech (Nanjing, China). Antibodies against Bax (\#2772), Bcl2 ( $\left.{ }^{4} 4223\right)$, Cytochrome c ( ${ }^{\# 11940)}$, Caspase-3 ( ${ }^{\# 9662),}$ cleaved caspase-3 ( ${ }^{\# 9661)}$, Caspase-8 (\#4790), cleaved caspase-8 (\#9496), Caspase-9 ("9508), NF-кB (p65, \#8242) and Histone H3 (\#3638) were purchased from Cell Signalling Technology (Danvers, MA, USA). Anti- $\beta$-actin and anti-GAPDH antibodies, anti-mouse and anti-rabbit horseradish peroxidase (HRP)-conjugated secondary
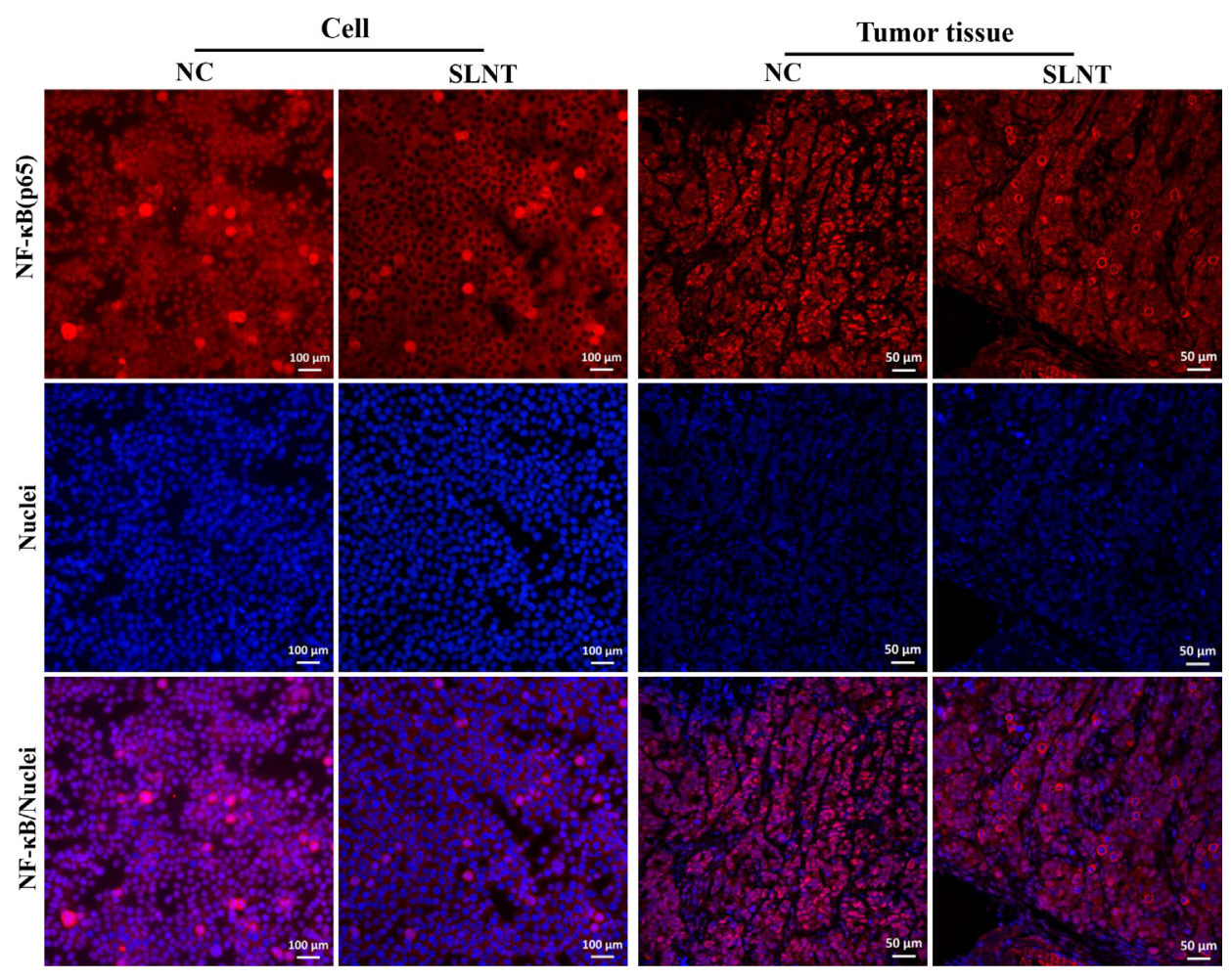

Figure 9: SLNT inhibited NF-кB p65 nuclear translocation both in vitro and in vivo. 
antibodies, 5-Fluorouracil (5-FU), MTT and standard sugar were purchased from Sigma (St. Louis, MO, USA). All other chemicals used were of analytical grade.

\section{Preparation and structure characterization of Lentinus edodes polysaccharide}

The dried fruit bodies of $L$. edodes were obtained from FangXian (Hubei, China). The polysaccharide from Lentinus edodes (SLNT) was extracted, isolated and purified as previously described [11]. Briefly, after soaking with $95 \%$ alcohol, the fruit body residues were subjected to water extraction followed by ethanol precipitation, decoloration and ultrafiltration. A yield of around $1.91 \mathrm{~g}$ of SLNT was obtained from $250 \mathrm{~g}$ of $L$. edodes, which sugar content was approximately $98.14 \%$ and molecular weight was $623.5 \mathrm{kDa}$. UV spectrophotometer scanning showed that SLNT was absence of proteins and nucleic acids (data were not shown). The structure of SLNT was determined as previously described [11, 14]. GC-MS analysis revealed that the monosaccharide composition of SLNT was glucose alone. SLNT was further determined as polysaccharide containing $\beta$-D-glucans with pyranose by FT-IR analysis. Moreover, the types of glucosidic linkages and the molar ratios of them were analyzed by periodate oxidation and methylation. Results showed that $\beta-(1 \rightarrow 3)$ D-glucose formed the backbone structure of SLNT and $\beta-(1 \rightarrow 6)-D$-glucose formed side chains, which ratio was closer to $3: 1$. The basic structural unit of SLNT was shown in Supplementary Figure S1.

\section{Cell line and culture}

Human colon cancer HT-29 cells, initially obtained from American Type Culture Collection (ATCC, Manassas, VA, USA), were maintained and grown in McCoy's 5A medium supplemented with $10 \%$ FBS and $1 \%$ penicillin/streptomycin. The cells were cultured at $37^{\circ} \mathrm{C}$ in a humidified atmosphere containing $5 \% \mathrm{CO}_{2}$.

\section{Cell viability assay}

The HT-29 cells were cultured in the absence or presence of SLNT $(0-800 \mu \mathrm{g} / \mathrm{mL})$ or 5 -FU $(800 \mu \mathrm{g} / \mathrm{mL})$ for $48 \mathrm{~h}$ and MTT assay was performed as previously described. Absorbance was measured at $570 \mathrm{~nm}$ using a microplate reader (Multiskan Mk3, Thermo Scientific, MA, USA).

\section{Flow cytometric analysis of apoptosis}

HT-29 cells were grown in a 6-well plate at $2 \times 10^{5}$ cells/well and treated with different concentrations of SLNT $(400,800,1600 \mu \mathrm{g} / \mathrm{mL})$ for $48 \mathrm{~h}$, with untreated cells as negative control (NC). The cells were harvested, washed twice with PBS and re-suspended in $500 \mu \mathrm{L}$ binding buffer. After being incubated with $5 \mu \mathrm{L}$ of

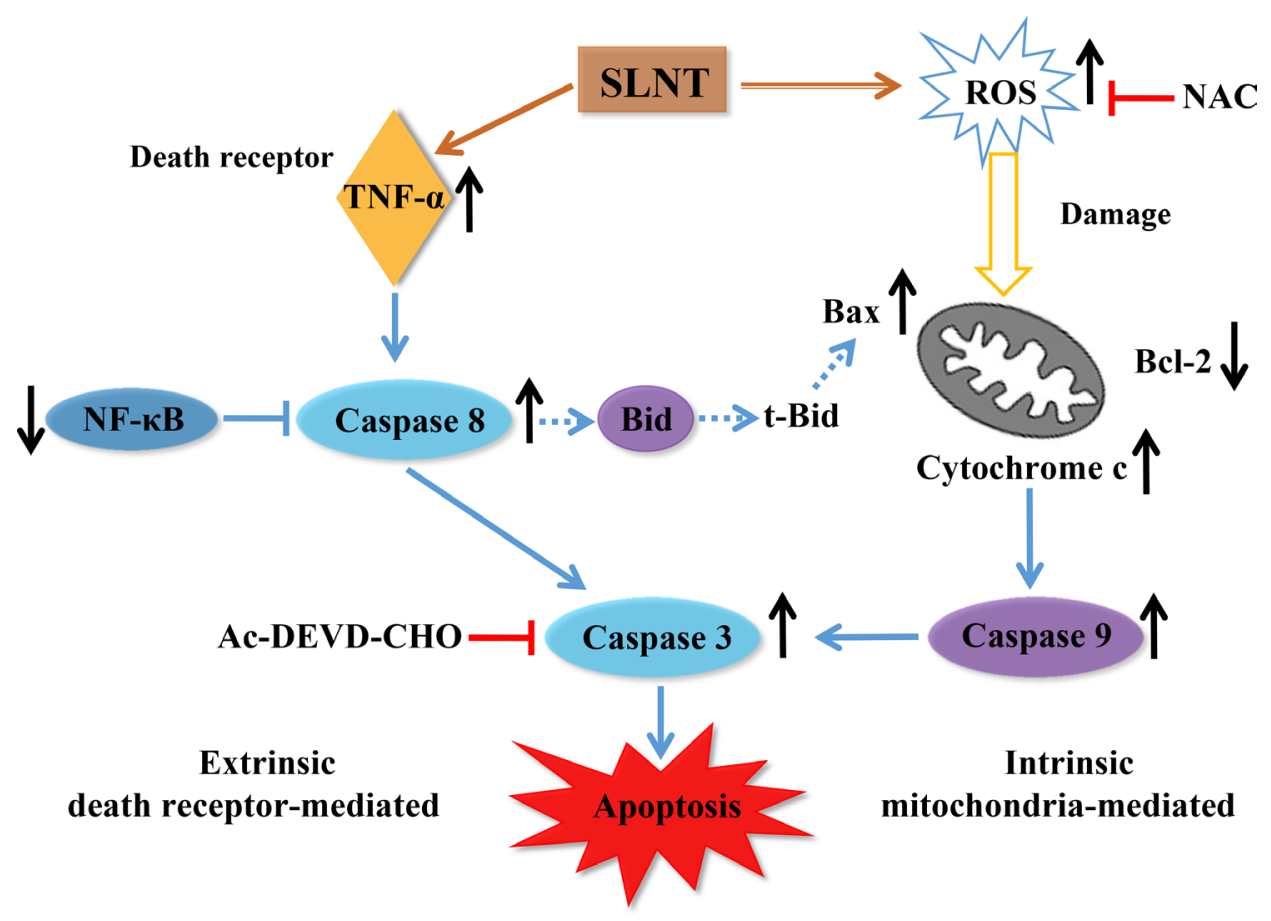

Figure 10: Flow diagram of the probable mechanism of direct antitumor effect of SLNT on HT-29 cells. 
Annexin V-FITC and $5 \mu \mathrm{L}$ of PI for 15 min, the cells were immediately analyzed by flow cytometry (BD, NJ, USA). Data analysis was performed using Flowjo V10 software.

\section{Morphological analysis}

\section{DAPI staining}

HT-29 cells were seeded in a 24 -well plate at $5 \times 10^{4} /$ well and treated with SLNT for $48 \mathrm{~h}$. The cells were washed and stained with DAPI at room temperature for $15 \mathrm{~min}$. Fluorescence was observed using a fluorescence microscope (DSY5000X, Chongqing, China).

\section{AO/EB staining}

Dye mixture of $1 \mu \mathrm{L}$ of $\mathrm{AO}(100 \mu \mathrm{g} / \mathrm{mL})$ and $1 \mu \mathrm{L}$ of EB $(100 \mu \mathrm{g} / \mathrm{mL})$ stained cells treated with SLNT or not for $10 \mathrm{~min}$. After staining, cells were washed twice with PBS and visualized under fluorescence microscope (Chongqing, China).

\section{Detection of mitochondrial membrane potential (MMP)}

The changes in the MMP of cells were assessed by JC-1 staining. Normally, healthy mitochondria was polarized and JC-1would be rapidly taken up into it as aggregates emitting in red. However, once $\Delta \Psi_{\mathrm{m}}$ depolarized, JC-1 would remain in the cytoplasm as monomers emitting in green. Thus the increase of ratio of green/red fluorescence indicated a loss of $\Delta \Psi_{\mathrm{m}}$. The detection was performed as manufacturer's instructions and analyzed by flow cytometry and fluorescence microscope.

\section{In vivo tumor xenograft study}

All nude mice experiments were approved by the Institution Animal Care and Use Committee of Tongji Medical College, Huazhong University of Science and Technology (SYXK-2010-0057) and all mice were treated according to the guidelines set forth by the National Association for Assessment and Accreditation of Laboratory Animal Care. Thirty 5-week-old male athymic nude mice (BALB/c-nu) purchased from HFK Bioscience (Beijing, China) were maintained under specific pathogenfree conditions in the Central Animal Facility of Union Hospital (Wuhan, China), and acclimated before the experiment. HT-29 cells $\left(3.75 \times 10^{6}\right)$ were injected subcutaneously into the right flank of nude mice (17-20 g in weight). Starting at 5 days post-injection, tumors were measured with calipers every other day and tumor size was calculated using the formula: $\mathrm{V}=\left(\mathrm{L} \times \mathrm{W}^{2}\right) / 2$, where $\mathrm{L}(\mathrm{mm})$ is the largest diameter and $\mathrm{W}(\mathrm{mm})$ is perpendicular to $\mathrm{L}$. The treatments started at a day after injection of cells. Animals were randomly divided into five groups ( $n=6$ /group) as follows: (i) sterile $0.9 \%$ saline (negative control); (ii) $0.2 \mathrm{mg} / \mathrm{kg} \mathrm{SLNT}$; (iii) $1 \mathrm{mg} / \mathrm{kg}$ SLNT; (iv) $5 \mathrm{mg} / \mathrm{kg} \mathrm{SLNT}$; and (v) $20 \mathrm{mg} / \mathrm{kg} 5-\mathrm{FU}$, and treated by intravenous (i.v.) injection through tail vein. SLNT was dissolved in sterile $0.9 \%$ saline and filtrated by $0.22 \mu \mathrm{m}$ microporous membrane (Millipore, USA) prior to use. The doses of SLNT and 5-FU were selected on the basis of previous experiments $[36,37]$ and our preliminary studies. Injections were performed every other day for 21 days. In the end of treatments, mice were euthanized; tumor xenografts and spleens were excised, weighed and stored at $-80^{\circ} \mathrm{C}$. The antitumor activity of SLNT was expressed as an inhibition rate calculated as follows: inhibition rate $(\%)=[(\mathrm{Wa}-\mathrm{Wb}) / \mathrm{Wa}] \times 100 \%$, where $\mathrm{Wa}$ and $\mathrm{Wb}$ were the average tumor weights of the control and experimental group, respectively.

\section{Measurement of ROS}

In vitro, ROS levels were measured by DCFH-DA. Briefly, after treatment with SLNT for 48 h, HT-29 cells cultured in 6-well plates were incubated with DCFH$\mathrm{DA}$ for $1 \mathrm{~h}$ at $37^{\circ} \mathrm{C}$ and then detected by fluorescence microscope and flow cytometry. In vivo, the concentration of ROS was measured by ELISA kits and analyzed at $450 \mathrm{~nm}$ by microplate reader.

\section{Measurement of TNF- $\alpha$}

The concentration of TNF- $\alpha$ in vitro and in vivo was measured by ELISA kits according to manufacturer's instructions. Briefly, the cell culture medium was harvested after SLNT treatment and the serum of mice was collected, separated and stored at $-80^{\circ} \mathrm{C}$ before detection. The samples were added to ELISA plate with sample diluent $(1: 4)$ and incubated at $37^{\circ} \mathrm{C}$ for $30 \mathrm{~min}$. Then, the plates were washed with wash buffer 5 times, added $50 \mu \mathrm{l}$ HRP conjugate each plate except control, incubated at $37^{\circ} \mathrm{C}$ for $30 \mathrm{~min}$ and washed again. Next, substrate reagent (TMB) was added. The plates were incubated at $37^{\circ} \mathrm{C}$ for $15 \mathrm{~min}$ in the dark, followed by addition of $50 \mu \mathrm{l}$ stop solution, and finally measured at $450 \mathrm{~nm}$ by microplate reader.

\section{H\&E staining}

Tumor tissues were fixed in $4 \%$ formalin, embedded in paraffin, sectioned and stained with haematoxylin and eosin (H\&E) for histopathological assay. The image was captured at $400 \times$ by an optical microscope (Caikon XSP$11 \mathrm{CD}$, Shanghai, China).

\section{Preparation of cytoplasmic and nuclear extracts}

Cytoplasmic extracts of cells and tumors were isolated from mitochondria using the Cell and Tissue Mitochondria Isolation Kits, respectively, according to 
the manufacturer's instructions. Cells and tissues nuclear extracts were prepared using Nuclear-Cytosol Extraction Kit as previously described [38]. Cytoplasmic and Nuclear extracts were collected and stored at $-80^{\circ} \mathrm{C}$ until use.

\section{Western blotting}

To examine the expression of Bax, Bcl-2, cytosol Cytochrome c, cleaved caspase-3, cleaved caspase-8, caspase-9, nuclear NF- $\mathrm{B}$ (p65), $\beta$-actin, GAPDH and Histone $\mathrm{H} 3$ proteins, Western blot analysis were performed as previously described [15]. The signal was visualized and evaluated by Image J software (National Institutes of Health, Bethesda, MD, USA).

\section{Immunofluorescence}

Translocation of NF- $\mathrm{BB}$ (p65) from cytoplasm to nucleus was detected by immunofluorescence. Briefly, cells and thawed tumor sections were fixed and permeabilized. Then, the samples were washed with PBS, blocked with goat serum, probed with primary NF- $\kappa$ B p65 antibody for $1 \mathrm{~h}$, and followed by incubation with cy3-conjugated secondary antibody for $1 \mathrm{~h}$. Additionally, before observed using a fluorescence microscope at 400×, the samples were stained with DAPI for nuclear staining.

\section{Immunohistochemistry}

HT-29 tumor samples were perfusion fixed with 4\% paraformaldehyde and stored in 70\% ethanol. Paraffinembedded tumor sections $(5 \mu \mathrm{m})$ were stained with antibodies against caspase- 3 and cleaved caspase- 8 using the method as previously described [15] and observed under an optical microscope at $400 \times$.

\section{Caspase-8 activity assay}

The activity of Caspase- 8 in HT-29 cells was detected using Caspase- 8 colorimetric activity assay kit, which is based on spectrophotometric detection of the chromophore $p$-nitroaniline ( $p \mathrm{NA}$ ) after cleavage from the labelled substrate Ac-IETD- $p$ NA by the active enzyme. The caspase- 8 activity was detected according to the manufacture's protocols. Absorbance (A) was measured at $405 \mathrm{~nm}$ using the microplate reader.

\section{Statistical analysis}

Dates presented as mean $\pm \mathrm{SD}$ and $p$ values were determined using an unpaired Student's $t$-test from the GraphPad Prism version 5.0 software (San Diego, CA, USA). A $p$-value $<0.05$ was considered as statistically significant.

\section{Abbreviations}

AO/EB: acridine orange and ethidium bromide; Ac-DEVD-CHO: N-Acetyl-Asp-Glu-Val-Asp-CHO; DAPI: 4, 6-diamidino-2-phenylindole; DCFH-DA: 2', 7'-Dichlorofluorescein diacetate; 5-FU: 5-Fluorouracil; NAC: N-acetylcysteine; NC: negative control; ROS: reactive oxygen species; SLNT: water-extracted polysaccharide from Lentinus edodes; TNF- $\alpha$ : tumor necrosis factor- $\alpha$

\section{ACKNOWLEDGMENTS AND FUNDING}

This work is supported by the National Natural Science Foundation of China (Grant No.81373300) and we would like to express our thanks to Analysis and Testing Center of Huazhong University of Science and Technology and the General Surgery of Union Hospital for the technical assistance.

\section{CONFLICTS OF INTEREST}

The authors declare that they have no conflicts of interest.

\section{REFERENCES}

1. Jemal A, Murray T, Ward E, Samuels A, Tiwari RC, Ghafoor A, Feuer EJ, Thun MJ. Cancer Statistics, 2005. CA-Cancer J Clin. 2005; 55:10-30.

2. Lin J, Qiu M, Xu R, Sandra Dobs A. Comparison of survival and clinicopathologic features in colorectal cancer among African American, Caucasian, and Chinese patients treated in the United States: Results from the surveillance epidemiology and end results (SEER) database. Oncotarget. 2015; 6:33935-43. doi: 10.18632/oncotarget.5223.

3. Wolpin BM, Mayer RJ. Systemic Treatment of Colorectal Cancer. Gastroenterology. 2008; 134:1296-1310.e1291.

4. Goldberg RM, Sargent DJ, Morton RF, Fuchs CS, Ramanathan RK, Williamson SK, Findlay BP, Pitot HC, Alberts SR. A randomized controlled trial of fluorouracil plus leucovorin, irinotecan, and oxaliplatin combinations in patients with previously untreated metastatic colorectal cancer. J Clin Oncol. 2004; 22:23-30.

5. Chau I, Cunningham D. Adjuvant therapy in colon cancer-what, when and how? Ann Oncol. 2006; 17: 1347-1359.

6. Bisen PS, Baghel RK, Sanodiya BS, Thakur GS, Prasad GBKS. Lentinus edodes: A Macrofungus with Pharmacological Activities. Curr Med Chem. 2010; 17:2419-2430.

7. Shida M, Haryu K, Matsuda K. On the water-soluble heterogalactan from the fruit bodies of lentinus edodes. Carbohydrate Res. 1975; 41:211-218. 
8. Wasser S. Medicinal mushrooms as a source of antitumor and immunomodulating polysaccharides. Appl Microbiol Biot. 2002; 60:258-274.

9. Kenji I, Takae K, Takafumi A. The Use of Lentinan for Treating Gastric Cancer. Anti-Cancer Agent Me. 2013; 13:681-688.

10. Maeda YY, Watanabe ST, Chihara C, Rokutanda M. Denaturation and renaturation of a beta-1,6;1,3-glucan, lentinan, associated with expression of T-cell-mediated responses. Cancer Res. 1988; 48:671-675.

11. Wang KP, Zhang QL, Liu Y, Wang J, Cheng Y, Zhang Y. Structure and inducing tumor cell apoptosis activity of polysaccharides isolated from Lentinus edodes. J Agr Food Chem. 2013; 61:9849-9858.

12. Gu YH, Belury MA. Selective induction of apoptosis in murine skin carcinoma cells $(\mathrm{CH} 72)$ by an ethanol extract of Lentinula edodes. Cancer Lett. 2005; 220:21-28.

13. Israilides C, Kletsas D, Arapoglou D, Philippoussis A, Pratsinis H, Ebringerova A, Hribalova V, Harding SE. In vitro cytostatic and immunomodulatory properties of the medicinal mushroom Lentinula edodes. Phytomedicine. 2008; 15:512-519.

14. Wang K-p, Wang J, Li Q, Zhang Q-1, You R-x, Cheng Y, Luo L, Zhang Y. Structural differences and conformational characterization of five bioactive polysaccharides from Lentinus edodes. Food Res Int. 2014; 62:223-232.

15. Zhang Y, Li Q, Shu Y, Wang H, Zheng Z, Wang J, Wang K. Induction of apoptosis in S180 tumour bearing mice by polysaccharide from Lentinus edodes via mitochondria apoptotic pathway. J Funct Foods. 2015; 15:151-159.

16. Butler LM, Hewett PJ, Fitridge RA, Cowled PA. Deregulation of apoptosis in colorectal carcinoma: theoretical and therapeutic implications. Aust Nz J Surg. 1999; 69:88-94.

17. Rupnarain C, Dlamini Z, Naicker S, Bhoola K. Colon cancer: genomics and apoptotic events. Bio Chem. 2004; 449 .

18. Watson AJM, Merritt AJ, Jones LS, Askew JN, Anderson E, Becciolini A, Balzi M, Potten CS, Hickman JA. Evidence for reciprocity of bcl-2 and p53 expression in human colorectal adenomas and carcinomas. Br J Cancer. 1996; 73:889-895.

19. Ding HF, Fisher DE. Induction of apoptosis in cancer: new therapeutic opportunities. Ann Med. 2002; 34:451-469.

20. Shalini S, Dorstyn L, Dawar S, Kumar S. Old, new and emerging functions of caspases. Cell Death Differ. 2015; 22:526-539.

21. Hengartner MO. The biochemistry of apoptosis. Nature. 2000; 407:770-776.

22. Galluzzi L, Vitale I, Abrams JM, Alnemri ES, Baehrecke EH, Blagosklonny MV, Dawson TM, Dawson VL, El-Deiry WS, Fulda S, Gottlieb E, Green DR, Hengartner MO, et al. Molecular definitions of cell death subroutines: recommendations of the Nomenclature
Committee on Cell Death 2012. Cell Death Differ. 2012; 19:107-120.

23. Elmore S. Apoptosis: A Review of Programmed Cell Death. Toxicol Pathol. 2007; 35:495-516.

24. Huerta S, Goulet EJ, Huerta-Yepez S, Livingston EH. Screening and detection of apoptosis. J Surg Res. 2007; 139:143-156.

25. Reis FS, Sousa D, Barros L, Martins A, Morales P, Ferreira IC, Vasconcelos MH. Leccinum vulpinum Watling induces DNA damage, decreases cell proliferation and induces apoptosis on the human MCF-7 breast cancer cell line. Food Chem Toxicol. 2016; 90:45-54.

26. Shao FY, Du ZY, Ma DL, Chen WB, Fu WY, Ruan BB, Rui W, Zhang JX, Wang S, Wong NS, Xiao H, Li MM, Liu X, et al. B5, a thioredoxin reductase inhibitor, induces apoptosis in human cervical cancer cells by suppressing the thioredoxin system, disrupting mitochondrion-dependent pathways and triggering autophagy. Oncotarget. 2015; 6:30939-56. doi: 10.18632/oncotarget.5132.

27. Adams JM, Cory S. The Bcl-2 Protein Family: Arbiters of Cell Survival. Science. 1998; 281:1322-1326.

28. Chipuk JE, Moldoveanu T, Llambi F, Parsons MJ, Green DR. The BCL-2 Family Reunion. Mol Cell. 2010; 37:299-310.

29. Lavik AR, Zhong F, Chang M-J, Greenberg E, Choudhary Y, Smith MR, McColl KS, Pink J, Reu FJ, Matsuyama S, Distelhorst CW. A synthetic peptide targeting the BH4 domain of Bcl-2 induces apoptosis in multiple myeloma and follicular lymphoma cells alone or in combination with agents targeting the BH3-binding pocket of Bcl-2. Oncotarget. 2015; 6:27388-402. doi: 10.18632/ oncotarget.4489.

30. Circu ML, Aw TY. Reactive oxygen species, cellular redox systems, and apoptosis. Free Radical Bio Med. 2010; 48:749-762.

31. Zou P, Chen M, Ji J, Chen W, Chen X, Ying S, Zhang J, Zhang Z, Liu Z, Yang S, Liang G. Auranofin induces apoptosis by ROS-mediated ER stress and mitochondrial dysfunction and displayed synergistic lethality with piperlongumine in gastric cancer. Oncotarget. 2015; 6:36505-21. doi: 10.18632/ oncotarget.5364.

32. Wang L, Tian Z, Yang Q, Li H, Guan H, Shi B, Hou P, Ji M. Sulforaphane inhibits thyroid cancer cell growth and invasiveness through the reactive oxygen species-dependent pathway. Oncotarget. 2015; 6:25917-31. doi: 10.18632/ oncotarget.4542.

33. Galluzzi L, López-Soto A, Kumar S, Kroemer G. Caspases Connect Cell-Death Signaling to Organismal Homeostasis. Immunity. 2016; 44:221-231.

34. Balkwill F. Tumour necrosis factor and cancer. Nat Rev Cancer. 2009; 9:361-371.

35. Karin M, Lin A. NF-[kappa]B at the crossroads of life and death. Nat Immunol. 2002; 3:221-227.

36. Maeda YY, Chihara G. The effects of neonatal thymectomy on the antitumour activity of lentinan, 
carboxymethylpachymaran and zymosan, and their effects on various immune responses. Int J Cancer. 1973; 11:153-161.

37. Guichard S, Cussac D, Hennebelle I, Bugat R, Canal P. Sequence-dependent activity of the irinotecan-5FU combination in human colon-cancer model HT-29 in vitro and in vivo. Int J Cancer. 1997; 73:729-734.
38. Wang GF, Wu SY, Xu W, Jin H, Zhu ZG, Li ZH, Tian YX, Zhang JJ, Rao JJ, Wu SG. Geniposide inhibits high glucoseinduced cell adhesion through the NF-kappaB signaling pathway in human umbilical vein endothelial cells. Acta Pharmacol Sin. 2010; 31:953-962. 